\title{
IN VITRO AND IN SILICO EVALUATION OF XANTHINE OXIDASE INHIBITORY ACTIVITY OF QUERCETIN CONTAINED IN SONCHUS ARVENSIS LEAF EXTRACT
}

\author{
RINI HENDRIANI ${ }^{1 *}$, NURSAMSIAR ${ }^{2}$, AMI TJITRARESMI $^{3}$ \\ ${ }^{1}$ Depatrment of Pharmacology and Clinical Pharmacy, Faculty of Pharmacy, Universitas Padjadjaran, Indonesia. ${ }^{2}$ Department of Analytical \\ Pharmacy and Medicinal Chemistry, Sekolah Tinggi Ilmu Farmasi Makassar, Indonesia. ${ }^{3}$ Department Biological Pharmacy, Faculty of \\ Pharmacy, Universitas Padjadjaran, Email: rini.hendriani@unpad.ac.id \\ Received: 04 November 2016, Revised and Accepted: 24 January 2017
}

ABSTRACT

Objective: The aim of the present study was to examine the inhibiting effects of quercetin contained in Sonchus arvensis leaf extract on the activity of xanthine oxidase, an essential enzyme for uric acid synthesis.

Methods: Activity test was conducted in vitro by measuring the activity of xanthine oxidase using ultraviolet spectrophotometry and in silico by determining the interaction of quercetin and allopurinol (as comparator drug) with xanthine oxidase enzyme in terms of hydrogen bonds and binding free energy. Docking simulations were performed by AutoDock 4.2 package.

Results: The active fraction, using the solvent n-hexane, ethyl acetate, and water, tested the inhibitory activity of the xanthine oxidase enzyme in vitro obtained, respectively, inhibitory concentration $50 \%$ of $263.19,16.20$, and $141.80 \mu \mathrm{g} / \mathrm{ml}$. Isolates with highest activity identified as quercetin. The xanthine oxidase enzyme inhibitory activity in silico by molecular docking showed that quercetin has free energy binding -7.71 kcal/mol, more negative than that of allopurinol $-5.63 \mathrm{kcal} / \mathrm{mol}$.

Conclusion: This shows the affinity of quercetin stronger than that of allopurinol so that it can be predicted that quercetin was more potential to inhibit xanthine oxidase enzyme activity. Thus, the extract of the $S$. arvensis leaves containing the active compound quercetin was a potential use as antihyperuricemia.

Keywords: Quercetin, Sonchus arvensis, Inhibitor, Xanthine oxidase, Hyperuricemia.

(c) 2017 The Authors. Published by Innovare Academic Sciences Pvt Ltd. This is an open access article under the CC BY license (http://creativecommons. org/licenses/by/4. 0/) DOI: http://dx.doi.org/10.22159/ajpcr.2017.v10s2.19486

\section{INTRODUCTION}

The trend of back to nature in using natural ingredients and herbs is increasing worldwide so that herbal medicine is an interesting treatment option to be developed. In Indonesia, Sonchus arvensis leaf has been traditionally used in as hyperuricemia remedy [1]. Hyperuricemia occurs due to excessive production of uric acid or low excretion of the acid or a combination of both [2]. Increased production of uric acid caused partly by the intake of foods that contain purine, uric acid metabolism disorder and breakdown of purines too quickly in the body also causes high levels of uric acid in the blood [3]. Decrease the excretion of uric acid is the main cause of hyperuricemia and can be caused by idiopathic primary, renal insufficiency, the interaction of drugs, and alcohol [3]. The combination of both mechanisms may occur in glucose-6-phosphatase deficiency and deficiency of fructose-1-phosphate aldolase [2]. The production of uric acid is catalyzed by xanthine oxidase in the liver [4]. Inhibition of xanthine oxidase can be one of the therapeutic avenues for the treatment of hyperuricemia. Xanthine oxidase is an essential enzyme for uric acid synthesis that converts hypoxanthine into xanthine and xanthine into uric acid, thus reducing uric acid production. Uric acid is the final product of purine metabolism in human body that exits the body through urinary excretion. This substance has very low solubility and tends to form crystals. Uric acid accumulated in the joints is commonly found in the form of monosodium uric crystals that induces inflammatory reactions $[5,6]$. Allopurinol is used clinically in the treatment of gout. Currently, allopurinol is one of the most widely used modern medicines to inhibit the synthesis of uric acid [2].

The results of previous studies of the structure-activity relationships and classification of flavonoids as an inhibitor of xanthine oxidase and superoxide scavengers were performed in vitro states that flavonoids are group of natural products that have various biological activities and pharmacological such as antibacterial, antiviral, antioxidant, antimutagenic effects and can inhibit some enzymes. Some flavonoids have been reported to inhibit the enzyme xanthine oxidase and have the ability to capture free radicals. Therefore, flavonoids can be used in the treatment of gout and ischemia in humans with lower levels of uric acid and free radicals in the body. One of them is the flavonoid quercetin, which is an inhibitor of the enzyme xanthine oxidase and has the ability to capture free radicals [7]. This is in line with the results of other studies stating that flavones and flavonols planar such as chrysin, luteolin, kaempferol, quercetin, myricetin, and isorhamnetin can inhibit xanthine oxidase enzyme strongly, while flavonoids non-planar, isoflavones, and anthocyanidins only slightly inhibit [8]. Quercetin is flavonol compounds that are widespread in plants [9]. In silico study was needed to analyze the xanthine oxidase enzyme inhibitory activity by predicting the affinity and interaction between quercetin and the xanthine oxidase enzyme.

Computational chemistry with in silico study described that in biological systems, the resulting pharmacological activity is not only dependent on the chemical structure or position of atoms that bind to receptors but also involves intermolecular force as a whole is important for proper interaction and complementarity between the two molecules. Among the various interactions between molecules, hydrogen bonds are very important. Hydrogen bonds work within a limited distance and direction, while the electrostatic interaction works in all directions and a greater distance [10]. Molecules with very different chemical structure can bind to the same site of the receptor. Many examples are known for competitive inhibition between the molecules of various structures. The shape and nature of the molecules should be complementary to the receptor sites [10]. The entire structure of drug molecules is not always necessary to bind to the receptor because not all the atoms of the inhibitor molecule 
involved in the interaction with the receptor protein [10]. This article presents the evaluation of complementary in terms of in silico and in vitro pharmacological activity-related quercetin contained in S. arvensis.

\section{METHODS}

\section{Plant materials}

S. arvensis leaf was collected from the botanical garden of Manoko in Lembang, West Java, Indonesia. The plant materials were authenticated at Herbarium Bandungense, the School of Life Sciences and Technology, and Bandung Institute of Technology.

\section{Plant extraction}

This study used the cold maceration method for extraction, with $96 \%$ ethanol extracting solvents for the dried and ground plant materials. The macerate accumulated was concentrated using rotary evaporator under reduced pressure.

\section{Xanthine oxidase inhibitory in vitro assay}

Activity test for xanthine oxidase inhibition was conducted in vitro using ultraviolet spectrophotometry as described in previous studies [4,11-13] with the slight modification. Xanthine oxidase enzyme from bovine milk (Sigma-Aldrich, Tokyo, Japan) was prepared by dilution of the enzyme to a final concentration 2 Units $/ \mathrm{ml} .1 \mathrm{mM}$ xanthine substrate solution was made by adding 5 drops of $1.0 \mathrm{M} \mathrm{NaOH}$ to increase the solubility of xanthine. Ethanolic extracts were dissolved in $1 \%$ dimethyl sulfoxide and made the test concentration at 50,100, and $200 \mathrm{mg} / \mathrm{ml}$. Allopurinol is used as comparator drug; total volume of the assay mixture was $3.2 \mathrm{ml}$ consisting of $1 \mathrm{ml}$ sample S. arvensis extract at various concentration, $1 \mathrm{ml}$ of $0.15 \mathrm{M}$ phosphate buffer ( $\mathrm{pH}$ 7.8), and $100 \mu \mathrm{l}$ solution of the enzyme xanthine oxidase. After pre-incubation of the test solution at $37^{\circ} \mathrm{C}$ for 15 minutes, the reaction was initiated by addition of $100 \mu$ l of xanthine substrate solution and incubated at $37^{\circ} \mathrm{C}$ for 30 minutes. The reaction was stopped by adding $1 \mathrm{ml}$ of $1 \mathrm{~N} \mathrm{HCl}$. Spectrophotometer absorbance at $295 \mathrm{~nm}$, suggesting the formation of uric acid. Percent of inhibition of xanthine oxidase activity of the test sample was determined by measuring the absorbance of uric acid from the mixture without test extracts (blank samples) compared with the absorbance of a mixture of test extracts. Inhibitory concentration $50 \%\left(\mathrm{IC}_{50}\right)$ values were obtained by linear regression analysis of a plot, a series of different sample concentrations against percent inhibition.

\section{Xanthine oxidase inhibitory in silico assay}

Xanthine oxidase inhibition assay was conducted in silico as described in previous studies [14-16] with the slight modification. The ligand binding domain 3D structure of bovine xanthine oxidase in complex with quercetin obtained from the Protein Data Bank (www.pdb.org) with PDB code $3 \mathrm{NVY}$ as well as quercetin and allopurinol. Preparation of ligands and receptors, docking process, and analysis was performed using the AutoDock Tools v.4.2 program package (http://autodock.scripps.edu).

\section{RESULTS AND DISCUSSION}

Examination compound of $S$. arvensis leaf extract by thin-layer chromatography GF254 with the mobile phase chloroform:ethyl acetate:formic acid (6:4:0.2) and comparison to quercetin standard on Rf 0.6 indicates quercetin contained in the extract. Indeed, previous studies of the evaluation of flavonoids and antioxidant activity in S. arvensis showed that one of the components contained in $S$. arvensis is quercetin [17]. Table 1 shows the results of inhibitory activity of the xanthine oxidase enzyme in vitro and obtained quercetin with

Table 1: The results of the inhibitory activity of the xanthine oxidase enzyme in vitro of quercetin and allopurinol

\begin{tabular}{lllll}
\hline \multirow{2}{*}{$\begin{array}{l}\text { Material } \\
\text { tested }\end{array}$} & \multicolumn{2}{c}{ Percent of inhibition (\%) } & \multirow{2}{*}{$\mathbf{I C}_{50}(\boldsymbol{\mu g} / \mathbf{m l})$} \\
\cline { 2 - 4 } & $\mathbf{5 0} \mathbf{\mu g} / \mathbf{m l}$ & $\mathbf{1 0 0} \boldsymbol{\mu g} / \mathbf{m l}$ & $\mathbf{2 0 0} \boldsymbol{\mu g} / \mathbf{m l}$ & \\
\hline Quercetin & $58.72 \pm 2.81$ & $75.67 \pm 2.05$ & $95.18 \pm 1.82$ & 4.39 \\
Allopurinol & $59.14 \pm 3.26$ & $71.38 \pm 7.01$ & $91.75 \pm 11.99$ & 4.84 \\
\hline
\end{tabular}

$\mathrm{IC}_{50} 4.39 \mathrm{mg} / \mathrm{mL}$, smaller than that of allopurinol $4.84 \mathrm{ug} / \mathrm{ml}$. Indeed, previous studies on the structure-activity relationships and classification of flavonoids as inhibitors of xanthine oxidase and superoxide scavengers were conducted in vitro and showed results that quercetin was a xanthine oxidase inhibitor with an additional superoxide scavenging activity [7].

Previous study showed that $S$. arvensis exhibits xanthine oxidase inhibitory activity and suggests that ethyl acetate extract of $S$. arvensis leaves has the most potent activity in inhibiting xanthine oxidase activity $[12,13]$. Sonchus arvensis L. leaves extract toxicity study showed there were no toxic effects after the use of single dose administration as acute toxicity test in mice, and also no toxic effects after repeated dose administration as subchronic oral toxicity studies in rats. Lethal dose of the extract was higher than $15 \mathrm{~g} / \mathrm{kg}$ bw and classified as practically non-toxic. There were no abnormalities in behavior, hematological, clinical biochemistry, and urine parameters [18].

Molecular docking simulations in this study were conducted to analyze the xanthine oxidase enzyme inhibitory activity by predicting the affinity and interaction between quercetin and the xanthine oxidase enzyme and compared with allopurinol. It was done through energy predictions bond conformation and orientation of molecules in the active site to target receptors and modeling the interactions between the receptor and the ligand. The crystal structure of bovine xanthine oxidase in complex with quercetin used as the target receptors obtained from the PDB (www. pdb.org) with PDB code 3NVY. Docking process using Genetic Algorithm Lamarckian facilities in AutoDock Tools v.4.2 program that ligands directed to various possible positions in the structure of target molecules [14]. Docking method validation was done by redocking natural ligand receptor on the active side. The validity of the docking method parameters evaluated based on the value root-mean-square deviation (RMSD) and declared valid if the value of RMSD smaller than $2.0 \AA$ [19]. In this study, the RMSD was $0.91 \AA$, indicating that methods and calculation parameter settings meet the criteria of validity docking methods. Fig. 1 shown the comparison of the natural ligand conformation, that is quercetin from X-ray crystal structure of the conformation obtained from the calculation with the docking parameter grid box coordinates $\mathrm{x}$; $\mathrm{y}$; and $\mathrm{z}$ were $39.512 ; 21.651$; and 20.246 .

Analysis was performed on free energy parameter binding; inhibition constants, hydrogen bonding, and interactions occurred between the ligand (quercetin and allopurinol) with amino acid residues at the active site receptors. The value of free energy can be used to predict the binding affinity and ability of a compound to inhibit the enzyme molecule [14]. Negative free energy of binding inhibition constants indicates good affinity between ligands and receptors. As shown in Table 2, quercetin in lowest conformation energy had free energy binding $-7.71 \mathrm{kcal} / \mathrm{mol}$, more negative than that of allopurinol $-5.63 \mathrm{kcal} / \mathrm{mol}$. This suggests the affinity of quercetin stronger than that of allopurinol so that it could be predicted that quercetin was more potential to inhibit xanthine oxidase enzyme. Indeed, previous research on finding study material that has potential as the enzyme xanthine oxidase inhibitor use in silico docking showed that flavonoids have interaction with the active site of the enzyme xanthine oxidase [15]. Previous studies report that

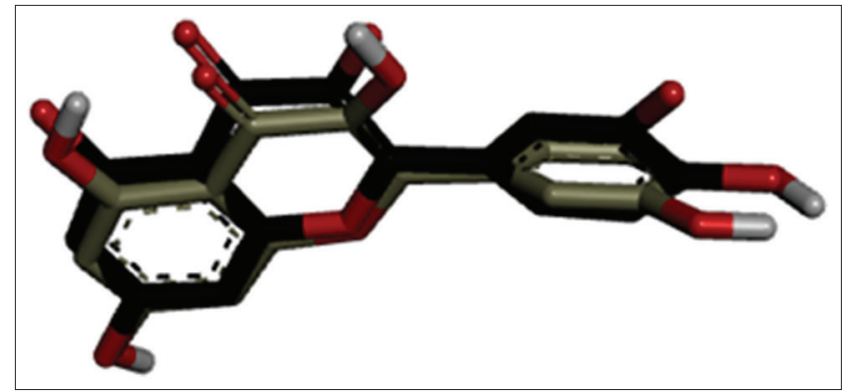

Fig. 1: The comparison between quercetin conformation of the natural ligand $X$-ray crystal structure (black) with the conformation obtained from docking calculations (gray) 
Table 2: The results of in silico molecular docking of quercetin and allopurinol

\begin{tabular}{|c|c|c|c|c|}
\hline Material tested & Conformation & Binding energy (kcal/mol) & Inhibition constant $(\mu \mathrm{M})$ & Intermolecular energy ( $\mathrm{kcal} / \mathrm{mol})$ \\
\hline \multirow[t]{9}{*}{ Quercetin } & 1 & -7.71 & 2.24 & -9.50 \\
\hline & 2 & -7.70 & 2.29 & -9.49 \\
\hline & 3 & -7.70 & 2.28 & -9.49 \\
\hline & 4 & -7.69 & 2.31 & -9.48 \\
\hline & 5 & -7.69 & 2.29 & -9.48 \\
\hline & 6 & -7.69 & 2.32 & -9.48 \\
\hline & 7 & -7.68 & 2.33 & -9.47 \\
\hline & 9 & -7.68 & 2.34 & -9.47 \\
\hline & 10 & -7.57 & 2.81 & -9.49 \\
\hline \multirow[t]{8}{*}{ Allopurinol } & 1 & -5.63 & 74.96 & -5.63 \\
\hline & 2 & -5.00 & 215.45 & -5.00 \\
\hline & 3 & -4.91 & 249.71 & -4.91 \\
\hline & 4 & -4.39 & 600.57 & -4.39 \\
\hline & 5 & -5.63 & 75.00 & -5.63 \\
\hline & 6 & -5.03 & 205.13 & -5.03 \\
\hline & 9 & -5.26 & 74.96 & -5.26 \\
\hline & 10 & -4.90 & 74.96 & -4.90 \\
\hline
\end{tabular}

the molecular modeling flavonoids could inhibit the xanthine oxidase enzyme. The apigenin, quercetin, myrisetin, isoviteksin, genistein, and naringenin were competitive inhibitor, and the kinetic analysis showed that flavonoids bind to the active site of the enzyme [16]. Likewise, another study using molecular docking showed that flavonoids provide inhibitory activity on the xanthine oxidase enzyme so as to further development for the prevention and treatment of gout and related inflammatory conditions [15].

Inhibition constants were proportional to the free energy of binding, $2.24 \mu \mathrm{M}$ quercetin smaller than allopurinol $74.96 \mu \mathrm{M}$ in the lowest conformation energy. It indicates quercetin easier to bind the xanthine oxidase enzyme than allopurinol. Quercetin showed intermolecular energy $-9.50 \mathrm{kcal} / \mathrm{mol}$ lower than allopurinol with $-5.63 \mathrm{kcal} / \mathrm{mol}$, thus reinforcing predictions that the inhibitory activity of quercetin was greater than allopurinol.

Figs. 2 and 3 shows that quercetin had two hydrogen bonds at amino acid residue Glu802 and Thr1010 as well as allopurinol can form hydrogen bonds at amino acid residue Thr1010 and Glu802. Indeed, previous studies showed that the complement steric benefit from the structure of quercetin in the active site of the receptor by hydrogen bonds with residual catalytic at Arg880 and Glu802 as an inhibitor of flavonoids against xanthine oxidase which is useful for the treatment of hyperuricemia, gout, and diseases of inflammation [20]. In another study, it is also explained that the disposition of the substrate in the active site Arg880 and Glu802 was important for the conversion of xanthine to uric acid [21]. Results of other studies explain that the xanthine oxidase inhibitor had hydrogen bonds to Glu802, Arg880, and Glu1261 essential for enzyme reactions [22]. Thus, it appears that both quercetin and allopurinol could bind to the active side of the enzyme xanthine oxidase.

Most of the plant flavonoid binding to the sugar clusters that tend to be soluble in water is rarely found as aglycone. Flavonoid glycosides absorption in the body is very light, just flavonoid aglycones be able to pass through the intestinal wall. Hydrolysis occurs in the large intestine by intestinal microflora; hydrolytic enzymes of the intestinal microflora could convert certain flavonoid glycosides into the aglycone form then passively diffuses into the cell and provide a pharmacological activity [23]. Thus, the extract of the $S$. arvensis leaves containing the active compound quercetin was a potential use as antihyperuricemia.

\section{CONCLUSION}

S. arvensis under investigation containing quercetin as active compound exhibits xanthine oxidase inhibitory activity. The energy bonding

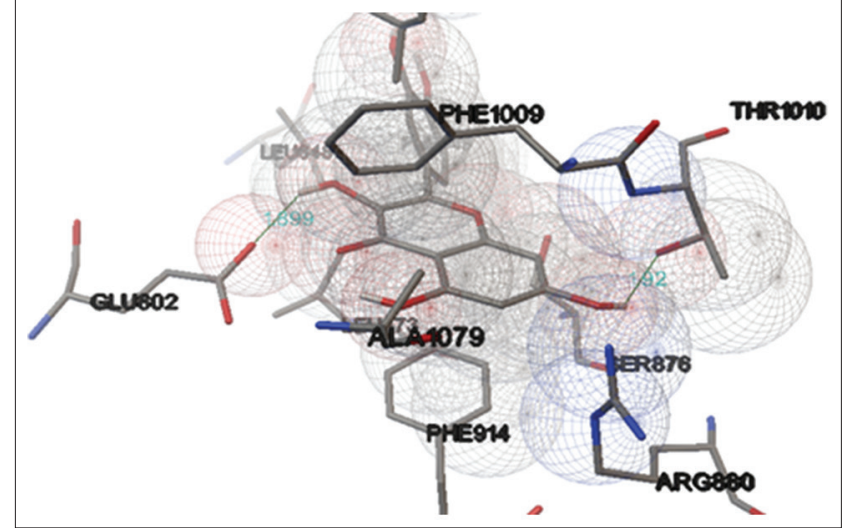

Fig. 2: The interaction of quercetin ligand on the active side xanthine oxidase receptor

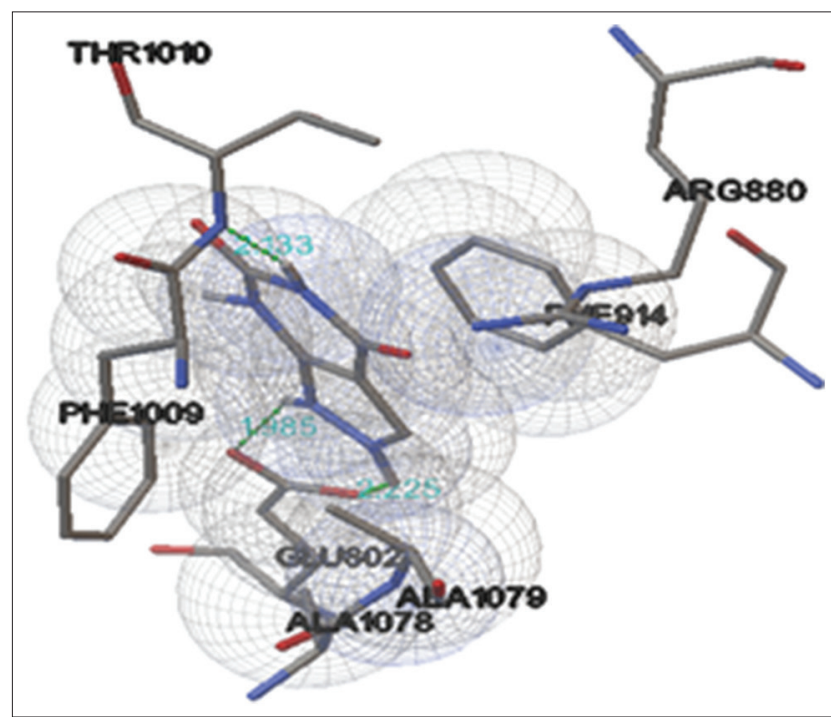

Fig. 3: The interaction of allopurinol ligand on the active side xanthine oxidase receptor

of quercetin was more negative compared to that of allopurinol, suggesting more affinity of quercetin to the active site of the enzyme. 
Indeed, the in vitro result showing lower $\mathrm{IC}_{50}$ of quercetin than that of allopurinol. Thus, the $S$. arvensis leaf was potential to be developed as agent for treating hyperuricemia.

\section{ACKNOWLEDGMENT}

We gratefully acknowledge the financial assistance received from Universitas Padjadjaran through research grant funding scheme to carry out this study.

\section{REFERENCES}

1. Dalimartha S. Atlas of Indonesian Medicinal Plants. $4^{\text {th }}$ ed. Jakarta: Penebar Swadaya; 2001.

2. Herfindal ET, Gourley DR, Hart LL. Clinical Pharmacy and Therapeutics. $5^{\text {th }}$ ed. Baltimore: Williams \& Wilkins; 1992.

3. Wortmann RL. Gout and Other Disorder of Purin Metabolism: Principles of Internal Medicine. 14 $4^{\text {th }}$ ed. New York: McGraw-Hill Companies; 1998

4. Bustanji Y, Hudaib M, Tawaha K, Mohammad KM, Almasri I, Hamed $\mathrm{S}$, et al. In vitro xanthine oxidase inhibition by selected Jordanian medicinal plants. Jordan J Pharm Sci 2011;4(1):49-56.

5. Dipiro JT, Talbert RL, Yee GC, Matzke G, Wells B, Posey LM. Pharmacotherapy: A Patophysiologic Approach. $7^{\text {th }}$ ed. New York: McGraw Hill; 2008.

6. Shafer SL, Fiset P. Clinical Pharmacy and Therapeutics. $5^{\text {th }}$ ed. Maryland: William \& Wilkins; 1992.

7. Cos P, Ying L, Calomme M, Hu JP, Cimanga K, Van Poel B, et al. Structure-activity relationship and classification of flavonoids as inhibitors of xanthine oxidase and superoxide scavengers. J Nat Prod 1998;61:71-6.

8. Nagao A, Seki M, Kobayashi H. Inhibition of xanthine oxidase by flavonoids. Biosci Biotechnol Biochem 1999;63(10):1787-90.

9. Harborne JB. Phytochemical Methods. A Guide to Modern Techniques of Plant Analysis. $3^{\text {rd }}$ ed. London: Chapman and Hall; 1988.

10. Itai A, Tomioka N, Kato Y. Rational approaches to computer drug design based on drug-receptor interactions. QSAR and Drug Design - New Developments and Applications. Vol. 3. New York: Elsevier Science; 1995. p. 48.
11. Azmi SM, Jamal P, Amid A. Xanthine oxidase inhibitory activity from potential Malaysian medicinal plant as remedies for gout. Int Food Res J 2012;19(1):159-65.

12. Hendriani R, Sukandar EY, Anggadiredja K, Sukrasno. In vitro evaluation of xanthine oxidase inhibitory activity of Sonchus arvensis leaves. Int J Pharm Pharm Sci 2014;6(2):501-3

13. Hendriani R, Sukandar EY, Anggadiredja K, Sukrasno. In vitro evaluation of xanthine oxidase inhibitory activity of selected medical plants. Int J Pharm Clin Res 2016;8(4):235-8.

14. Kartasasmita RE, Herowati R, Harmastuti N, Gusnidar T. Quercetin derivatives docking based on study of flavonoids interaction to cyclooxygenase-2. Indones J Chem 2009;9(2):297-302.

15. Umamaheswari M, Madeswaran A, Asokkumar K, Sivashanmugam T, Subhadradevi V, Jagannath P. Discovery of potential xanthine oxidase inhibitors using in silico docking studies. Pharm Chem 2011;3(5):240-7.

16. Lin CM, Chen CS, Chen CT, Liang YC, Lin JK. Molecular modeling of flavonoids that inhibits xanthine oxidase. Biochem Biophys Res Commun 2002;294(1):167-72

17. Khan RA. Evaluation of flavonoids and diverse antioxidant activities of Sonchus arvensis. Chem Cent J 2012;6(1):126.

18. Nurianti Y, Hendriani R, Sukandar EY, Anggadiredja K. Acute and subchronic oral toxicity studies of ethyl acetate extract of Sonchus arvensis L. Leaves. Int J Pharm Pharm Sci 2014;6(5):343-7.

19. Trott O, Olson AJ. AutoDock Vina: Improving the speed and accuracy of docking with a new scoring function, efficient optimization, and multithreading. J Comput Chem 2010;31:455-61.

20. Cao H, Pauff JM, Hille R. X-ray crystal structure of a xanthine oxidase complex with the flavonoid inhibitor quercetin. J Nat Prod 2014;77(7):1693-9.

21. Cao H, Pauff JM, Hille R. Substrate orientation and catalytic specificity in the action of xanthine oxidase: The sequential hydroxylation of hypoxanthine to uric acid. J Biol Chem 2010;285(36):28044-53.

22. Okamoto K, Eger BT, Nishino T, Pai EF, Nishino T. Mechanism of inhibition of xanthine oxidoreductase by allopurinol: Crystal structure of reduced bovine milk xanthine oxidoreductase bound with oxipurinol. Nucleosides Nucleotides Nucleic Acids 2008;27(6):888-93.

23. Thilakarathna SH, Rupasinghe HP. Flavonoid bioavailability and attempts for bioavailability enhancement. Nutrients 2013;5(9):3367-87. 